\title{
AS NARRATIVAS DIDÁTICAS SOBRE O BANDEIRANTE: ENTRE A MITOLOGIA BANDEIRANTE E A CRÍTICA HISTÓRICA ${ }^{1}$
}

\author{
Andressa da Silva Gonçalves ${ }^{2}$ \\ Mauro Cezar Coelho ${ }^{3}$
}

\begin{abstract}
Resumo: Os livros didáticos disponibilizados pelo Programa Nacional do Livro Didático (PNLD) se constituem hoje como um dos recursos mais importantes para alunos e professores nas escolas públicas brasileiras. Os livros didáticos de história articulam o conhecimento historiográfico consolidado e a memória histórica construída. Neste trabalho, procuramos verificar como História e Memória se inserem na literatura didática, na abordagem da temática das Entradas e Bandeiras. Percebemos nos livros analisados uma complexa relação entre o saber de referência e a memória histórica: dimensionados em distintas camadas narrativas esses saberes veiculam diferentes interpretações sobre o mesmo processo histórico. A coexistência dessas camadas discursivas revela a complexidade cultural do livro didático, que conjuga em si ecos da memória bandeirante e as contribuições da historiografia contemporânea.
\end{abstract}

Palavras-chave: Livro didático. Ensino de História. Bandeirante. Cultura Histórica.

\section{THE DIDACTIC NARRATIVES ABOUT THE BANDEIRANTE: BETWEEN THE BANDEIRANTE MYTHOLOGY AND THE HISTORICAL CRITICISM}

\begin{abstract}
The didactic book made available by the National Didactic Book Program (PNLD) is today one of the most important resources for students and teachers in Brazilian public schools. History didactic books articulate consolidated historiographic knowledge and constructed historical memory. In this work, we try to verify how History and Memory are inserted in the didactic literature, in the approach of the theme of Entries and Flags. We perceive in the analyzed books a complex relationship between reference knowledge and historical memory: dimensioned in different narrative layers, this knowledge conveys different interpretations about the same historical process. The coexistence of these discursive layers reveals the cultural complexity of the didactic books, which combines in itself echoes of the Bandeirante memory and the contributions of contemporary historiography.
\end{abstract}

Keywords: Didactic book. History teaching. Bandeirante. Historical Culture.

\footnotetext{
1 Este artigo é resultado da pesquisa realizada para a monografia: As narrativas didáticas sobre as Entradas e Bandeiras, no passado colonial nos livros didáticos consumidos na região norte (1995-2016), apresentada a Universidade Federal do Pará. Este trabalho se vincula também ao subprojeto: Narrativa Histórica e Função Pedagógica: O Passado Colonial na Literatura Didática 1995-2012, sob orientação do professor Dr. Mauro Cezar Coelho, que por sua vez se insere no projeto Usos do passado: história pública, didática e formação do professor, coordenado pela professora Dra. Helenice Aparecida Bastos Rocha.

${ }^{2}$ Graduada em história pela Universidade Federal do Pará (UFPA). Atualmente realiza o mestrado no programa de pós-graduação em história social da Amazônia (PPHIST/UFPA). A pesquisa em curso se debruça sobre as representações sobre Entradas e Bandeiras nas narrativas didáticas.

${ }^{3}$ Possui graduação em Bacharelado História pela Universidade Federal Fluminense (1994), graduação em Licenciatura História pela Universidade Federal Fluminense (1994), mestrado em História Social da Cultura pela Pontifícia Universidade Católica do Rio de Janeiro (1996) e doutorado em História Social pela Universidade de São Paulo (2006). Professor Adjunto da Universidade Federal do Pará, onde atua na Faculdade de História e no Programa de História Social da Amazônia. Tem experiência na área de História, com ênfase em História Colonial e Ensino de História, atuando principalmente nos seguintes temas: Amazônia colonial, história indígena e do indigenismo, história da ciência, história da educação e ensino de história.
} 


\section{LES RÉCITS DIDACTIQUES SUR LE BANDEIRANTE: ENTRE LA MYTHOLOGIE BANDEIRANTE ET LA CRITIQUE HISTORIQUE}

Résumé: Les manuels mis à disposition par le Programme national des manuels scolaires (PNLD) sont aujourd'hui l'une des ressources les plus importantes pour les élèves et les enseignants des écoles publiques brésiliennes. Les manuels d'histoire articulent les connaissances historiographiques consolidées et la mémoire historique construite. Dans ce travail, nous essayons de vérifier comment l'histoire et la mémoire sont inclus dans la littérature didactique, dans l'approche du thème des entrées et des drapeaux. Nous percevons dans les livres analysés une relation complexe entre la connaissance de référence et la mémoire historique, dimensionnée dans différentes couches narratives, ces connaissances se trouvent différentes interprétations sur le même processus historique. La coexistence de ces couches discursives révèle la complexité culturelle du manuel, qui combine en soi des échos de la mémoire bandeirante et les contributions de l'historiographie contemporaine.

Mots-clés: Manuel. Enseignement de l'histoire. Bandeirante. Culture historique.

\section{LAS NARRATIVAS DIDÁCTICAS SOBRE EL BANDEIRANTE: ENTRE LA MITOLOGÍA BANDEIRANTE Y LA CRÍTICA HISTÓRICA}

Resumen: Los libros de texto disponibles por el Programa Nacional de Libros de Texto (PNLD) se constituyen actualmente como uno de los recursos más importantes para estudiantes y maestros en las escuelas públicas brasileñas. Los libros de texto de historia articulan el conocimiento historiográfico consolidado y construyen la memoria histórica. En este trabajo, tratamos de verificar cómo la Historia y la Memoria se incluyen en la literatura didáctica, con enfoque en el tema de Entradas y Banderas. Percibimos en los libros analizados una compleja relación entre el conocimiento de referencia y la memoria histórica: dimensionados en diferentes capas narrativas, estos conocimientos manifiestan diferentes interpretaciones sobre el mismo proceso histórico. La coexistencia de estas capas discursivas revela la complejidad cultural del libro de texto, que combina en sí mismo ecos de la memoria bandeirante y los aportes de la historiografía contemporánea.

Palabras clave: Libro de texto. Enseñanza de Historia. Bandeirante. Cultura Histórica.

Que história tem sido veiculada nos livros didáticos? Essa pergunta tem ocupado o campo do Ensino de História e tem suscitado discussões acerca do livro didático, como suporte da narrativa histórica escolar (SILVA, 2013). O debate envolve tanto o currículo subjacente à narrativa proposta pelo livro didático quanto a relação entre o saber escolar e o saber historiográfico.

O livro didático permanece como elemento essencial em nosso sistema de ensino. Em que pesem os impactos da rede mundial de computadores no acesso à informação, é na Escola que a maior parte das crianças e adolescentes inseridos na Educação Básica tem contato com o saber histórico sistematizado. E o livro didático é o grande mediador nesse sentido, independentemente do modo como ele é apropriado. Gerações de brasileiros construíram uma visão de Brasil e de passado brasileiro, tendo os livros didáticos como o principal provedor de acesso à História e à Memória.

Mas, o livro didático de História não é um mero reprodutor ou um vulgarizador do saber historiográfico. Entre nós, ele conjuga uma série de narrativas que dão conta 
tanto do saber acadêmico institucionalizado quanto da memória histórica consagrada. Se, por um lado, ele reitera a Memória, por outro, ele contribui para a transgressão de visões consolidadas sobre o nosso passado e nossa formação. O livro didático é, pois, um bem cultural complexo.

A análise do modo pelo qual as Entradas e Bandeiras são abordadas em livros didáticos de História, aprovados pelo Programa Nacional do Livro Didático, é o caminho que adotamos para discutir a natureza complexa do livro didático e o modo pelo qual ele agrega diferentes camadas discursivas. A seguir, situamos, suscintamente, o livro didático de História e sua relação com o saber histórico escolar, a construção da Memória bandeirante, a produção historiográfica sobre as Entradas e Bandeiras e o modo pelo qual a temática é abordada em livros didáticos. A análise da inserção da temática na literatura didática será realizada tendo como escopo documental três títulos didáticos: as coleções Teláris, Vontade de saber e Piatã $\tilde{a}^{4}$.

Argumentamos que os livros didáticos analisados compreendem diferentes camadas narrativas, as quais cumprem funções distintas, relacionadas à cultura escolar, aos processos de formação docente e ao mercado editorial. Nesse sentido, o livro didático reúne vários discursos, com o objetivo de tornar-se o mais amplo e acessível, satisfazendo públicos diferentes, interessados no livro didático.

\section{Livro didático - currículo e memória}

Os manuais didáticos fazem parte do panorama do livro no Brasil, desde meados do século XIX. Com a emergência das primeiras escolas, eles se tornaram um elemento importante. Inicialmente importados da Europa e demarcados pela influência francesa (SILVA, 2012, p. 807), passaram a ser produzidos aqui. A segunda metade do século XIX assiste a emergência de vários livros didáticos, produzidos por intelectuais brasileiros, vários deles ligados ao Instituto Histórico e Geográfico Brasileiro, em diversas províncias. O fato republicano concorreu para a consolidação da escrita didática, conformando uma narrativa canônica sobre a História do Brasil (NOVO, 2020).

Em sua avassaladora maioria, tais livros reproduziam uma narrativa construída desde aquele instituto, segundo a qual a história do Brasil se desdobrava da história europeia. Esses livros concorreram de modo decisivo para a construção de uma

\footnotetext{
${ }^{4}$ AZEVEDO; SERIACOPI, 2012; PELLEGRINI; DIAS; GRINBERG, 2015; RIBEIRO; ANASTASIA,
} 2015. 
memória da trajetória brasileira. Eles perpetuaram a noção da história como uma galeria de heróis nacionais, de grandes vultos e de eventos marcantes. Um conjunto de exemplos a serem apreendidos pelas novas gerações. A considerar a produção didática da última década do século XX, pilares da nossa cultura, como o mito das três raças, ainda ecoavam em suas páginas (COELHO, 2009).

Ao longo de todo esse período, o livro didático tornou-se um fator fundamental no sistema educacional. Base curricular, suporte de formação continuada, material de consulta e fonte para planejamento, o livro didático assumiu uma série de outras atribuições que fizeram dele um bem cultural complexo (SILVA, 2012). Além disso, desde há alguns anos, ele é objeto de um processo de avaliação sistemática, encaminhado por especialistas, que analisam e recomendam as coleções que serão adquiridas pelo Estado e distribuídas aos alunos e alunas das escolas públicas do país (JARDIM, 2010, p. 44). Ele se tornou, também, um dos mais importantes produtos do mercado editorial (FERREIRA; FRANCO, 2008).

A conformação do Programa Nacional do Livro Didático promoveu uma mudança na produção de livros didáticos ${ }^{5}$. As avaliações atentam para a qualidade das obras, sopesando a presença de equívocos conceituais, de manifestações de preconceito e do recurso a estereotipias, entre outros fatores. Elas concorreram para uma certa homogeneização do currículo proposto pela literatura didática. (CASSIANO, 2007, p. 58-59) Um dos fatores considerados pela avaliação é a atualização de conteúdos. Os editais do PNLD deixam claro que os livros didáticos devem estar em consonância com o desenvolvimento do conhecimento historiográfico ${ }^{6}$.

\footnotetext{
${ }^{5}$ O Programa Nacional do Livro Didático conforma uma política educacional, condizente com o estatuto da Educação no país, estabelecido a partir da Constituição de 1988. Instituído em 1985, inicialmente, limitava-se à aquisição e distribuição de livros. É em 1996, que o programa adquire os contornos atuais, passando a ser financiado pelo Fundo Nacional do Desenvolvimento para a Educação (FNDE), e, ainda mais importante, uma avaliação dos livros didáticos realizada por especialistas é inserida nos moldes do programa. Cf. OLIVEIRA; FREITAS, 2013, p. 10; HÖFLING, 2000.

${ }^{6}$ FUNDO NACIONAL DE DESENVOLVIMENTO DA EDUCAÇÃO. Programa Nacional Do Livro Didático para o ano de 2002 (PNLD/2002): Edital de convocação para inscrição no Processo de Avaliação e Seleção de Livros Didáticos a serem incluídos no "Guia de Livros Didáticos de $5^{\mathrm{a}} \mathrm{A} 8^{\mathrm{a}}$ Séries" do PNLD/2002. Brasília: FNDE, 1999, p. 55. (cópia digitalizada) idem. Programa Nacional Do Livro Didático para o ano de 2005 (PNLD/2005): Edital de convocação para inscrição no Processo de Avaliação e Seleção de Livros Didáticos a serem incluídos no "Guia de Livros Didáticos de $5^{\mathrm{a}} \mathrm{A} 8^{\mathrm{a}}$ Séries" do PNLD/2005. Brasília: FNDE, 2002, p. 54-55. (cópia digitalizada); idem. Programa Nacional Do Livro Didático - PNLD 2008: Edital de convocação para inscrição no Processo de Avaliação e Seleção de Obras Didáticas a serem incluídas no Guia de Livros Didáticos para os Anos Finais do Ensino Fundamental - PNLD/2008. Brasília: FNDE, 2005, p. 46;48. Disponível: https://www.fnde.gov.br/index.php/programas/programas-do-livro/consultas/editais-programas-

livro/item/3014-editais-anteriores. Acesso: 14 mai. 2020; idem. Programa Nacional Do Livro Didático PNLD 2011: Edital de convocação para inscriçãa no Processo de Avaliação e Seleção de Coleções Didáticas para o Programa Nacional do Livro Didático - PNLD 2011. Brasília: FNDE, 2008, p. 48.
} 
As exigências do processo de avaliação fazem com que as editoras submetam obras que dialogam com vários públicos: com os professores e professoras da Educação Básica, com as secretarias estaduais de educação, com os alunos e alunas, com a sociedade civil etc. (ROCHA, 2013, p. 54-55). Para fazer frente a essa complexa rede de demandantes, os livros didáticos são conformados por diversas camadas narrativas: o texto base, as caixas de texto, as imagens, as atividades avaliativas etc. (COELHO, 2017).

Duas delas nos interessam particularmente: as representadas pelo texto base e pelas caixas de texto. Conforme demonstraremos, a seguir, nas coleções analisadas, a partir da temática das Entradas e Bandeiras, enquanto no texto base o compromisso com a memória é reiterado, nas caixas de texto o saber historiográfico é dimensionado. $\mathrm{O}$ caso das Entradas e Bandeiras é exemplar, nesse sentido. No texto base, geralmente, encontramos uma narrativa atrelada a memória que alude às glórias esboçadas por uma memória construída no final do século XIX e no início do século XX. Nele, a mitificação dos bandeirantes é assumida como história. Já nos anexos e seções alheias ao texto principal, surge uma narrativa diferente, constituída por discussões historiográficas recentes, problematizações de fontes, imagens e símbolos bandeirantes.

\section{Memória bandeirante}

A distinção entre História e Memória tem sido largamente discutida, desde a constituição da história profissional, a partir da segunda metade do século XIX. A sistematização de procedimentos de pesquisa, considerando os processos de coleta e crítica da documentação e, sobretudo, a produção de conhecimento conceitualmente informada contribuiu para a distinção entre essas duas formas de apreensão do passado (CARBONEL, 1981, p. 91-110).

Jacques Le Goff (1996, p. 29), no seu clássico texto "História" assume a Memória como "mítica, deformada, anacrônica", constituindo o vivido da relação entre

\footnotetext{
Disponível em: https://www.fnde.gov.br/index.php/programas/programas-do-livro/consultas/editaisprogramas-livro/item/3014-editais-anteriores. Acesso: 14/05/2020; idem. EDITAL DE CONVOCAÇÃO 06/2011 - CGPLI: Edital de convocação para inscrição no Processo de Inscrição e Avaliação de Coleções Didáticas para o Programa Nacional do Livro Didático - PNLD 2014. Brasília: FNDE, 2011, p. 65. Disponível em: https://www.fnde.gov.br/index.php/programas/programas-do-livro/consultas/editaisprogramas-livro/item/3963-pnld-2014-anos-finais-do-ensino-fundamental. Acesso em: 14 mai. 2020; idem. EDITAL DE CONVOCAÇÃO 02/2015 - CGPLI: Edital de convocação para inscrição no Processo de Inscrição e Avaliação de Obras Didáticas para o Programa Nacional do Livro Didático - PNLD 2017. Brasília: FNDE, 2015, p. 58. Disponível em: https://www.fnde.gov.br/index.php/programas/programasdo-livro/consultas/editais-programas-livro/item/6228-edital-pnld-2017. Acesso em: 14 mai. 2020.
} 
presente e passado, enquanto a História é crítica da Memória, tendo como uma de suas principais funções esclarecê-la, corrigindo seus erros. A Memória, no entanto, é uma forma de elaboração histórica, posto que se trata de uma forma de apropriação do passado (LE GOFF, 1996, p. 49). Uma forma apaixonada, parcial e, eventualmente, isenta da crítica profissional. Entre nós, como em outras paragens, a relação entre História e Memória se constituiu sem que ambas fossem delimitadas por fronteiras precisas. As singularidades de nossa trajetória como país e como nação acabaram por promover Memória e História como instâncias análogas, comprometidas com os mesmos objetivos. A produção do Instituto Histórico e Geográfico Brasileiro é exemplar, nesse sentido.

Em que pesem os compromissos daquele instituto com a História, foram as diretrizes da Memória que ordenaram a sua produção. Desde seu início, a produção do instituto esteve comprometida com a formação de uma narrativa mais afeita aos interesses e paixões das elites representadas pelos seus associados. Assim, entre nós, a História esteve vinculada a uma certa interpretação do passado, mais ligada à Memória que às diretrizes nascentes da disciplina, daí seu caráter eurocêntrico, sua matriz excludente e seu compromisso com certas estruturas de nossa cultura como o racismo e seus desdobramentos [como a ideologia do branqueamento, o culto aos grandes vultos e a valorização de um viés conservador] (MATTOS, 2011, p. 9-18; GUIMARÃES, 2011; CHALOUB, 2009, LESSA, 2008; SILVA, 2009 ).

O caso das Entradas e Bandeiras não é diferente. A construção de uma Memória bandeirante caminhou pari passu à produção historiográfica, confundindo-se com ela. As bases da historiografia que iniciou os estudos sobre as ações e eventos que conformaram o que denominamos de Entradas e Bandeiras não excluiu princípios da conformação da Memória. Não por acaso, alguns reconhecem a existência de uma mitologia bandeirante: um "[...] conjunto de narrativas e tradições referentes à imagem do bandeirante enquanto fundador da nacionalidade e símbolo do paulista" (SOUZA, 2007, p. 151). Essa mitologia que situa o bandeirante no panteão da República e alçou-o à condição de símbolo máximo do ethos paulista foi construída na tensão entre Memória e História.

Nos primeiros anos do século XX, São Paulo já se encontrava em acelerado processo de modernização. O desafio que se impunha à elite paulista era preservar o seu prestígio e, ao mesmo tempo, unir os diferentes setores sociais que começavam a surgir com a industrialização sob um mesmo sentimento de pertencimento regional. Para 
alcançar tais objetivos, a figura épica do bandeirante foi instrumentalizada, como afirma Thaís Waldman (2015, p. 3).

A figura do bandeirante remediaria a heterogeneidade e amenizaria os conflitos sociais. Assim, a partir de documentos, mapas e crônicas dos séculos anteriores, o bandeirante começa a habitar o cotidiano paulista. Na década de 1920, esse personagem já era extremamente popular e uma lembrança constante para todos os setores da sociedade paulista.

Para Waldman (2015, p. 3-4), o bandeirante ao mesmo tempo em que era uma figura capaz de unir todos os setores da sociedade e assim construir uma identidade histórica homogênea, também tinha a função de separar as antigas famílias paulistas de um grupo de imigrantes que acabara de chegar. O mesmo bandeirante acionado para unir a população, permitia a distinção de um grupo de pessoas que se consideravam descendentes dos fundadores da cidade de São Paulo. Essa valorização acontecia por meio de narrativas históricas e literárias, muitas vezes financiadas pelo governo de São Paulo.

Os intelectuais que davam corpo à exaltação desse personagem, se sentiam deslocados frente ao Instituto Histórico e Geográfico Brasileiro, e pretenderam delinear a história paulista por meio da criação do Instituto Histórico e Geográfico de São Paulo. A disseminação de várias representações dos bandeirantes foi largamente incentivada por Washington Luís que, além de fazer parte do instituto paulista, ocupou a prefeitura da capital (1914-1919), o governo do estado (1920-1924) e, mais tarde, a presidência da República (1926-1930). A sua enorme influência política lhe permitiu apoiar diversas publicações sobre o tema, além de incentivar a popularização do bandeirante. Ele promoveu a exibição de filmes, a encomenda de pinturas e estátuas que representassem o bandeirante (WALDMAN, 2015).

Como salienta Ricardo Luiz de Souza (2007, p. 154), os bandeirantes serviriam de elo na ligação temporal e identitária entre os antigos desbravadores e os grupos de poder ligados à cafeicultura e ao governo. Nesse sentido, a valorização de um passado grandioso, protagonizado pelos desbravadores paulistas, se coadunava aos propósitos políticos de reconhecimento da importância de São Paulo no contexto nacional.

Havia, então, uma série de demandas da política, das paixões regionais, dos interesses das elites paulistas que concorreram para a construção da mitologia de que trata Ricardo Souza. Mas, foi na arena historiográfica que aquela mitologia ganhou corpo, pois foram os estudiosos paulistas que deram sustentação acadêmica à elevação 
dos bandeirantes ao panteão paulista e nacional. Não obstante, dois intelectuais legaram ao bandeirante o papel de formadores da Pátria, antes da empreitada paulista. Embora seus trabalhos não se voltassem especificamente para o bandeirante, Francisco Adolfo de Varnhagen e João Capistrano Honório de Abreu situaram o bandeirante como agente destacado, em suas obras clássicas.

Adolfo Varnhagen (1854, p. 322) percebeu o bandeirante como um agente civilizador, responsável pelo desbravamento das terras brasileiras, o que lhe garantia o atributo de herói da nação. Capistrano, por sua vez, adotou uma visão menos apaixonada evidenciando a violência e a barbárie sertanista. Todavia, o autor de Capítulos de História Colonial reconhecia a importância dos bandeirantes paulistas no desbravamento de novas terras (ABREU, 1998).

Capistrano, além de legar uma importante interpretação do movimento bandeirante, também foi responsável por conduzir outros estudiosos ao tema. Seus dois pupilos, Afonso d'Escragnolle Taunay e Paulo Prado, também pertencentes à elite paulista, estão entre os que mais se destacaram na construção da mitologia bandeirante (ABUD, 1985, p. 133). Afonso Taunay em seu vasto estudo sobre as bandeiras, considera o movimento de vital importância na história brasileira, tornando o objetivo de suas obras restaurar a glória bandeirante paulista nos anais da história. Seus estudos tinham como finalidade, também, retrucar as diversas críticas feitas por estudiosos estrangeiros aos desbravadores paulistas, para isso o autor empreendeu a tarefa de contar minuciosamente as glórias bandeirantes ${ }^{7}$.

Paulo Prado foi historiador das bandeiras e, também, participante ativo do movimento modernista, da década de 1920. Sendo membro importante da oligarquia política, seu trabalho também se prestou à produção ideológica de sua classe. As duas obras escritas por Prado, Paulística e Retrato do Brasil, tinham um ponto central: "a afirmação e o desenvolvimento de uma única tese: a de que a história do Brasil como um todo depende da história particular de São Paulo" (ALMEIDA, 2015, p. 137).

Afonso Taunay, por sua vez, também teve seus discípulos: Alfredo Ellis Júnior e Alcântara Machado. Alfredo Ellis direcionou seus estudos para a análise da mestiçagem bandeirante (ELLIS JÚNIOR, 1936). Desta forma, por meio do acionamento das teorias raciais, em voga no começo do século XX, Ellis Júnior tentou justificar a superioridade

\footnotetext{
${ }^{7}$ Taunay foi um dos intelectuais que mais publicou livros, até para o contexto atual, sua obra principal 'História Geral das Bandeiras' (1924) conta com onze volumes e quase cinco mil páginas (CAVALCANTE, 1994).
} 
defendida pela intelectualidade paulista: com uma abordagem interdisciplinar, o estudioso buscava salientar a diferenciação racial paulista frente ao resto do Brasil. Como John Monteiro (2001, p. 201) salienta em sua obra, "Populações paulistas... tinha a intenção de provar a eugenia de São Paulo e sua distinção perante ao resto do país no presente".

Alcântara Machado estudou as condições econômicas e sociais que demarcaram a vida do bandeirante (ABUD, 1985, p. 133). Em sua única obra, Vida e morte do bandeirante (1929), Machado não se concentrou nas grandes ações bandeirantes, mas, sim, nas diversas facetas do cotidiano paulista, não deixando de destacar os aspectos heroicos e a distinção racial dos desbravadores. Apesar de se distinguir pela análise da vida cotidiana paulista, as aproximações com a mitologia bandeirante ainda são suficientes para considerar a obra deste autor, juntamente com a de Afonso Taunay e de Alfredo Ellis, "matrizes do conhecimento sobre as bandeiras e o bandeirismo, produzido no século XX” (ABUD, 1985, p. 133).

Por último, destacamos entre os intelectuais responsáveis pela criação da mitologia bandeirante, Cassiano Ricardo que, com sua obra 'A marcha para o oeste' (1940), inaugurou uma nova interpretação apologética do bandeirante. Enquanto os autores anteriores situavam o movimento bandeirante como característica intrínseca ao planalto paulista, Ricardo apontou o sertanista como agente formador não apenas de São Paulo, mas também de todo o Brasil. Tal perspectiva em muito estava vinculada com o apoio do intelectual ao governo varguista, todo a obra foi projetada para "pensar a bandeira como gênese do Estado Novo" (ABUD, 1985, p. 197).

Como se vê, a produção de análises históricas sobre as Entradas e Bandeiras, de autores inseridos no Instituto Histórico e Geográfico de São Paulo, não prescindiu dos caracteres da Memória. Os autores que participaram da construção uma mitologia bandeirante fizeram largo uso de estratégias mais comprometidas com o contexto político com o qual estavam comprometidos que com os limites da disciplina. Sem prejuízo do lugar que ocupam na historiografia sobre tema, claro está a sua relação com a memória vinculada aos interesses de uma dada elite.

\section{Bandeirantes nas narrativas escolares}

Nesta seção abordaremos alguns pontos discutidos anteriormente. Nosso corpo documental se constitui pelas coleções Teláris, Vontade de Saber e Piatã, publicadas em 2013 e 2015. Nossa escolha por estes livros se justifica por serem exemplares 
relativamente atuais, avaliados por dois guias recentes disponibilizados pelo PNLD (Guia do PLND, 2014, p. 114-119; Guia do PNLD, 2017, p. 51-104). Salienta-se que, segundo o $\mathrm{FNDE}^{8}$, as coleções aqui citadas estão entre as mais adquiridas pelas escolas, a coleção Teláris foi a $5^{\circ}$ coleção mais vendida no ciclo de 2014 com 716.650 mil exemplares, já as coleções Vontade de Saber e Piatãa, foram a $3^{\circ}$ e $10^{\circ}$ coleções mais compradas no ciclo de 2017, com, respectivamente, 1.162 .104 e 216.941 títulos adquiridos pelas escolas. Logo, analisaremos um conteúdo didático que fez parte da formação recente de uma considerável parcela do público escolar, além de terem sido instrumentos de trabalho e de consulta dos professores desses estudantes. Tendo como base este escopo documental, refletimos, em primeiro lugar, sobre a presença da mitologia bandeirante nestas coleções, em seguida, abordaremos em que espaço da narrativa didática tal perspectiva mítica se encontra, e por fim, a sobreposição de camadas narrativas.

Antes de tudo, é preciso situar a organização dos livros didáticos quanto à exposição da temática bandeirante. Vejamos como ela se dá nas três coleções didáticas que analisamos. A temática das entradas e bandeiras é encaminhada em capítulos específicos, divididos em tópicos que buscam melhor organizar a discussão. Esses capítulos são iniciados com uma pequena introdução que busca situar o aluno em relação ao assunto, tal apresentação se repete em todos os capítulos dos livros analisados. Após a introdução, todas as coleções organizam tópicos com diferentes apontamentos que visam abarcar as diversas etapas do processo bandeirante. Eles têm como título: "Os bandeirantes", “As bandeiras de preação", "A procura por minerais preciosos”, “As bandeiras de prospecção", “A exploração do interior” (PELLEGRINI; DIAS; GRINBERG. 2015, $7^{\circ}$ ano) "Os bandeirantes", “A colonização do interior" (AZEVEDO; SERIACOPI. 2013., $7^{\circ}$ ano) "Entradas e Bandeiras" e "Em busca do Ouro" (RIBEIRO; ANASTASIA. 2015, $8^{\circ}$ ano) ${ }^{9}$. Nestes tópicos, percebemos três espaços recorrentes: o texto base, as caixas de texto e as imagens. Cada um deles assume uma função diferente na exposição da temática. Por fim, para concluir o

\footnotetext{
8 Dados Estatísticos: PNLD 2014. Disponível em: <https://www.fnde.gov.br/index.php/programas/programas-do-livro/pnld/dados-estatisticos-anosanteriores $>$. Acesso em: 28 Jun. 2010. Dados Estatísticos: PNLD 2017. Disponível em: https://www.fnde.gov.br/index.php/programas/programas-do-livro/pnld/dados-estatisticos. Acesso em: 28 jun. 2010.

${ }^{9}$ É importante salientar que o roteiro narrativo destacado nas três coleções didáticas analisadas neste trabalho se repete em um número maior de coleções didáticas, como demonstrado em trabalho anterior. Cf. GONÇALVES, 2018.
} 
capítulo, os autores inserem seções complementares de reflexão e análise, assim como exercícios sobre o assunto exposto.

As três coleções estudadas, de maneira geral, apresentam no texto-base o mesmo roteiro para expor o assunto para o aluno. No primeiro tópico das coleções, se caracterizam o movimento bandeirante e os seus integrantes, estes explicitamente relacionados à São Paulo e aos seus habitantes. Na coleção Teláris, no tópico 'Os bandeirantes', aponta-se que as expedições iniciaram por conta da necessidade da mão de obra para a agricultura paulista, sendo a definição de bandeiras as "expedições em busca de indígenas sertão a dentro [...] As pessoas que participavam delas eram os bandeirantes, também chamados de sertanistas" (AZEVEDO; SERIACOPI. 2013, $7^{\circ}$ ano, p. 212). Já na coleção Vontade de Saber, o tópico 'Os bandeirantes' assinala que os colonos paulistas necessitavam de mão de obra para os seus cultivos e "organizavam expedições que percorriam o interior do território brasileiro [...] Essas expedições eram chamadas de bandeiras e seus membros ficaram conhecidos como bandeirantes". (PELLEGRINI; DIAS; GRINBERG. 2015, $7^{\circ}$ ano, p. 260). Finalmente, a coleção Piatã, com o tópico 'Entradas e bandeiras', salienta a pobreza de São Paulo que, com uma economia de subsistência, necessitava de mão de obra para as lavouras: tal conjuntura “estimulou os exploradores paulistas a organizar expedições particulares pelo sertão para aprisionar indígenas [...] As expedições particulares foram chamadas de bandeiras. Seus integrantes, os bandeirantes...” (RIBEIRO; ANASTASIA. 2015, $8^{\circ}$ ano, p. 27).

Como se vê, os primeiros apontamentos realizados pelas coleções consistem em definir o que seriam as expedições bandeirantes, situando-as em decorrência das condições paulistas e da ação dos habitantes da vila de São Paulo. A narrativa didática, então, relaciona o fato bandeirante à São Paulo. Entretanto, esse vínculo é resultado de uma construção. Como indica Waldman (2015, p. 5), a definição de bandeirante como um colono paulista se consolida na década de 1930, quando aparece descrita em dicionários da língua portuguesa. Maria Queirós (1992), em pesquisa nos dicionários publicados entre 1802 e 1960, percebe uma crescente associação entre o bandeirante e o paulista, que culminou com o estado de sinonímia. Logo, a associação encaminhada pelos livros didáticos resulta de uma lenta construção ocorrida entre os séculos XIX e XX.

Nas coleções estudadas, são caracterizados os diferentes tipos de expedições bandeirantes, como as bandeiras de apresamento de índios e aquelas voltadas para a busca por metais e pedras preciosas. Em relação a essa divisão do bandeirantismo em 
diferentes fases, é importante frisar que os autores didáticos recorrem à historiografia paulista que inaugurou essa interpretação do movimento, pois as produções acadêmicas mais recentes rechaçam tal segmentação. Como destaca John Monteiro (1994, p. 57-60), apesar da tentativa de muitos estudiosos em dividir o bandeirantismo em fases, as expedições sempre tiveram um objetivo principal: "a necessidade crônica da mão-deobra indígena [...] todas as expedições tinham características comuns: voltavam com muitos cativos e sem nenhuma riqueza mineral".

Salienta-se também a periodização do movimento feita pelos exemplares analisados, estes apontam dois momentos fundamentais no bandeirismo: o início do século XVII é destacado como a origem das expedições bandeirantes, já o fim deste século é apontado como o período em que se descobrem as minas de ouro e se inicia a economia aurífera. É indispensável destacar também que as três coleções não se utilizam de referências bibliográficas durante o texto-base, as poucas obras historiográficas citadas estão inseridas nas caixas de texto e atividades. Na coleção Teláris, a única referência à historiografia durante a temática das Entradas e Bandeiras está na sessão 'Olho-vivo' que promove a análise de uma pintura, e se utiliza como fonte para a problematização o artigo 'Nas matas com poses de reis: a representação de bandeirantes e a tradição da retratística monárquica europeia’ de Paulo César Garcez Martins. Já na coleção Vontade de Saber a utilização da historiografia se situa exclusivamente em uma atividade em que o livro 'Dicionário do Brasil Colonial' de Ronaldo Vainfas é elencado para a problematização das diferentes representações do bandeirante. Finalmente, na coleção Piatã nenhuma referência é elencada em qualquer espaço da narrativa. Logo, o suporte acadêmico utilizado nas coleções é escasso e quando existe é limitado a espaços alheios ao texto principal. As narrativas didáticas destacam também as consequências dessas expedições: a interiorização e a expansão da colonização portuguesa para territórios ainda desconhecidos e a descoberta de metais e pedras preciosas. Todas estas questões fazem parte do roteiro narrativo acionado pelas coleções, que divide a temática em tópicos, estes entremeados com caixas de texto e imagens que acrescentam outras perspectivas a narrativa.

Constatamos nas coleções analisadas ecos de uma cultura histórica que mitifica o bandeirante. Eles se encontram no texto-base e nas imagens que o acompanham, as quais, na maior parte dos casos, são produções artísticas dos séculos XIX e XX, sem contextualização. Nessas camadas narrativas, se verifica a permanência de aspectos da mitologia bandeirante, por meio da exaltação das realizações paulistas, em estreita 
consonância com o que afirmaram os historiadores paulistas que abordamos na seção anterior. Senão vejamos.

A seguir, apresentamos alguns extratos do texto base, das três coleções. Estes trechos pertencem ao último tópico das coleções e explanam sobre os legados bandeirantes, ou seja, a colonização do interior e a descoberta do ouro. Neles, tópicos da mitificação bandeirante podem ser percebidos:

Essas expedições ampliariam ainda mais as fronteiras da colônia portuguesa e seriam responsáveis pelo nascimento de vilas e povoados em seu interior. Em alguns pontos do trajeto, pequenos grupos de pessoas estabeleciam-se e ficavam encarregados de cultivar alimentos, como mandioca e milho, para que na volta as bandeiras tivessem comida. Muitas dessas paradas deram origem a povoados, outros núcleos nasceram da descoberta de ouro ou de pedras preciosas. Esse foi o caso de Goiás (no atual estado Goiás), que tem sua origem em 1725 com a descoberta de ouro. Essa é também a origem de multas cidades do atual estado de Minas Gerais. (AZEVEDO; SERIACOPI. 2013., $7^{\circ}$ ano, p. 213)

Os bandeirantes paulistas encontraram as primeiras minas de ouro, em uma região próxima à atual cidade de Ouro Preto, em Minas Gerais [...] As expedições promovidas pelos bandeirantes tornaram conhecidas para a Coroa portuguesa vastas regiões do interior do território brasileiro, localizadas além dos limites do Tratado de Tordesilhas. (PELLEGRINI; DIAS; GRINBERG. $2015,7^{\circ}$ ano, p. 261)

Em 1693 chegaram notícias sobre a descoberta de ouro nas minas dos Cataguases e nos sertões do Caeté, nome dado a toda a região que, mais tarde, seria chamada Minas Gerais. Em 1719, descobriu-se ouro no atual estado de Mato Grosso do Sul; em 1726, em terras do atual estado de Goiás... (RIBEIRO; ANASTASIA. 2015, $8^{\circ}$ ano, p. 27)

Como se pode notar, os textos-base ressaltam a descoberta de riquezas minerais e a expansão do território. No primeiro fragmento, retirado da coleção Teláris e situado no tópico 'A colonização do interior', se enfatiza que as expedições bandeirantes foram responsáveis pela expansão da Colônia Portuguesa, discorrendo sobre as cidades fundadas pelos sertanistas, em decorrência da busca pelas minas de ouro. Já no segundo trecho, da coleção Vontade de saber, posicionado no tópico 'A exploração do interior', os autores salientam a descoberta de ouro pelos bandeirantes paulistas, assim como o desbravamento de terras incultas. Enfim, no último excerto, a coleção Piatã no tópico 'Em busca de ouro' destaca a descoberta de ouro em territórios ainda desconhecidos.

Nesse sentido, as três narrativas convergem ao destacar o legado bandeirante: o alargamento das fronteiras e a descoberta de riquezas minerais. É importante perceber que tal argumento foi construído por uma produção histórica que buscava evidenciar a liderança paulista, apontando suas contribuições para a formação e o enriquecimento do 
país. Como aponta Kátia Abud (1985, p. 27), tais ‘conquistas’ não eram reivindicadas e nem percebidas pelos sertanistas paulistas, tais legados apenas começaram a ser capitalizados nos séculos XIX e XX, com a construção de um aparato cultural e acadêmico para a valorização da paulistanidade. As narrativas didáticas, nos casos analisados, incorporam argumentos disseminados pela mitologia bandeirante, sem questionamentos evidentes no texto base.

A expansão do território colonial português se deu em função de diversos fatores. Certamente que as expedições de apresamento de indígenas concorreram para o domínio sobre territórios reclamados pela Coroa Espanhola, segundo o Tratado de Tordesilhas. Mas, não exclusivamente. Assumir a construção do território brasileiro como façanha bandeirante, implica em desconsiderar outros fatores que concorreram no processo. Conforme aponta a historiografia sobre o Tratado de Madri e, depois, sobre o Tratado de Santo Ildefonso, fatores geopolíticos pautaram o alargamento do território colonial português na América ao Norte e o seu estreitamento ao Sul (CORTEZÃO, 2001; SOARES, 1939, p. 131-140; CASTELO-BRANCO, 1985, p. 133-134; TAMBS, 1996, p. 165-179). Ademais, o território brasileiro deriva do território colonial português, mas outras forças políticas foram determinantes para a unificação e a consolidação do território nacional.

Como apontamos, percebemos nas três coleções vestígios de uma cultura histórica que concebe o bandeirante como herói, responsável por grandes proezas, como a expansão do território brasileiro e a descoberta de riquezas minerais. Salientamos que tais indícios são alocados no texto-base, que em grande parte reflete tal interpretação do bandeirante. Desta forma, o texto base incorpora em seus quadros perspectivas concebidas pela memória histórica e consolidadas pela historiografia paulista que forjaram o bandeirante como um herói nacional.

A incorporação da Memória ao longo do texto principal, fica ainda mais evidente quando visitamos outros espaços da narrativa didática, como caixas de texto, seções e atividades, já que eles revelam outra interpretação do movimento bandeirante. Enquanto, o texto base ressalta aspectos cristalizados pela memória, estes espaços realizam uma crítica a essa mesma memória, ressaltando questões esquecidas pelo texto- base:

Essas conquistas territoriais tiveram um alto preço para os indígenas. Ao resistir contra a invasão dos sertanistas, milhares deles foram exterminados. Os que não morreram foram capturados e escravizados [...] Financiados pelo governo do 
estado de São Paulo, artistas criaram pinturas e esculturas nas quais os bandeirantes eram representados como íntegros, corajosos, austeros, limpos e determinados... (AZEVEDO; SERIACOPI. 2013, $7^{\circ}$ ano, p. 214-215)

Nas gravuras tradicionais, os bandeirantes são representados como homens brancos imponentes e bem equipados, usando longas botas e largos chapéus. Estudos recentes mostram que a realidade era diferente: além de bandeirantes brancos, havia muitos mestiços. Eles costumavam andar descalços, possuíam poucos equipamentos, preferindo usar, na maioria das vezes, facões, espadas, arcos e flechas. (PELLEGRINI; DIAS; GRINBERG. 2015, $7^{\circ}$ ano, p. 261)

Os excertos acima pertencem respectivamente a coleção Teláris e Vontade de saber, e fazem parte de seções alheias ao texto base. O primeiro trecho pertence a uma seção complementar intitulada 'Olho vivo' localizada no fim do capítulo, neste espaço os autores da coleção Teláris, Gislane Azevedo e Reinaldo Seriacopi (2013, $7^{\circ}$ ano, p. 214-215) realizam a análise de uma pintura de Benedito Calixto intitulada 'Domingos Velho e seu assistente Antônio Fernandes de Abreu', a narrativa ressalta o contexto histórico e a versão dos acontecimentos que esta obra queria repassar, inserindo uma problematização da mitificação do bandeirante (reflexão totalmente ignorada no textobase). O segundo fragmento, pertencente a coleção Vontade de Saber, foi retirado de uma caixa de texto denominada 'A representação do bandeirante': o extrato localizado no fim da temática também analisa a pintura 'Domingos Velho e seu assistente Antônio

Fernandes de Abreu'. Os autores da coleção, Marco Pellegrini, Adriana Dias e Keila Grinberg problematizam a representação dos sertanistas na pintura, já que esta indica uma interpretação épica do bandeirante. A partir dos fragmentos, percebemos que nas seções complementares e caixas de texto são realizadas análises minuciosas das imagens, e mais que isso, estas fontes são relacionadas com uma problematização da representação épica da qual fazem parte.

Observa-se também que a discussão historiográfica ausente no texto-base ganha lugar nos demais espaços. A referência ou até a menção à história acadêmica não tem lugar no texto base, que realiza uma narrativa descritiva e linear dos acontecimentos. Parece-nos que os autores escolhem as seções complementares, caixas de texto e exercícios para acrescentar este ponto a narrativa:

O bandeirantismo e os bandeirantes figuram entre os grandes mitos da historiografia brasileira, sobretudo a produzida em São Paulo [...] no século XIX e início do século XX. O viajante francês Saint-Hilaire [...] encantou-se com as conquistas dos paulistas e escreveu sobre os longos percursos das bandeiras e a expansão territorial, considerando-os como pertencentes a uma "raça de gigantes". Essa expressão tornou-se célebre ponto de referência para a criação do herói bandeirante. Taunay e Alfredo Elis Jr. Historiadores do início 
do século XX, consideraram os bandeirantes como responsáveis pela atual dimensão territorial do Brasil... (PELLEGRINI; DIAS; GRINBERG. 2015, $7^{\circ}$ ano, p. 284)

O fragmento acima está presente na seção de atividades da coleção Vontade de Saber, o texto, de autoria de Ronaldo Vainfas, e discute a historiografia que consolidou a heroicização bandeirante, assim como também aponta historiadores que revisitaram e questionaram o mito sertanista. Além dos autores mencionados no excerto, o texto discutirá também as obras de Oliveira Viana, Capistrano de Abreu, Viana Moog e Alcântara Machado, apontando, assim, alguns representantes da historiografia bandeirante. Depois do texto de Vainfas, os autores elencam uma série de perguntas que estimulam o aluno a refletir sobre o mito bandeirante e as perspectivas dos diferentes historiadores referidos pelo fragmento. Destaca-se que a inclusão do saber de referência na narrativa e sua consequente problematização está restrita a seção de atividades.

Percebemos que as atividades propostas nas coleções incentivam os/as alunos/as a realizarem uma reflexão crítica em relação ao assunto exposto e as fontes elencadas ao longo da narrativa. Vejamos o que propõe a coleção Teláris:

[...] b) Descreva no caderno a relação dos bandeirantes com os indígenas. c) Quais foram os elementos utilizados pelo pintor Benedito Calixto para exaltar a figura de Domingos Jorge Velho na imagem das páginas 214 e 215? D) Como vimos, o quadro foi feito em 1903, bastante tempo depois da morte de Domingos Jorge Velho. Explique, no caderno, com que interesse ele foi encomendado. e) Com base nas informações que temos hoje a respeito da vida dos bandeirantes, identifique dois elementos na imagem que não correspondem à realidade vivida por esses homens. (AZEVEDO; SERIACOPI. 2013, $7^{\circ}$ ano, p. 216)

Como mostra o excerto, a atividade direciona os estudantes a refletirem não apenas sobre a temática exposta anteriormente, mas principalmente sobre uma fonte histórica e o contexto em que foi produzida. Assim, tais atividades instigam que os apontamentos anteriormente realizados, principalmente pelas caixas de texto, também passem pela interpretação e problematização do leitor.

Dado o exposto, percebemos duas camadas discursivas na literatura didática analisada. A primeira presente no texto-base evoca, como demonstrado, o eco de uma mitologia bandeirante presente na memória e corroborada pela historiografia paulista, em que se reivindicava ao colono paulista o status de herói regional e nacional. Tal postura pode ser percebida pela reiteração constante dos feitos gloriosos paulistas, principalmente a expansão territorial e a descoberta das minas de ouro e pedras 
preciosas. Como vimos, as narrativas didáticas, especificamente o texto principal, reproduzem tais argumentos, promovendo a permanência da memória mítica.

A segunda camada narrativa, presente nos espaços alheios ao texto principal, como caixas de texto, seções complementares e atividades, expõem, preponderantemente, a problematização da memória bandeirante, por meio da discussão de pinturas, símbolos e da historiografia apologética paulista. A presença de tal perspectiva contrasta e até contradiz a narrativa presente no texto principal, visto que reflete aspectos edificados pela memória. Logo, com a análise de três coleções de livros didáticos, inferimos que a estrutura didática expõe distintas interpretações sobre a temática bandeirante. Deste modo, as coleções revelam um duplo sentido: enquanto tentam alicerçar seus apontamentos no saber de referência, também recorrem à memória para construir a narrativa didática. De acordo com Le Goff (1996, p. 16), é papel do saber histórico corrigir a versão tradicional dos acontecimentos históricos. No caso da literatura didática, Memória e História convivem em tensão permanente já que, embora a historiografia recente tenha reelaborado a perspectiva alicerçada na memória, os livros didáticos ainda retificam aquela memória comprometida com a mitologia bandeirante, por meio do texto base e a criticam nas caixas de texto.

Tendo como referência estudos anteriores (ROCHA, 2013; CAIMI, 2017) e a análise realizada neste trabalho, acreditamos que a tensão se deve à tentativa das editoras em atender diferentes demandas que são direcionadas ao livro didático. Ao inserir uma abordagem tradicional, linear e cronológica do tema, presente no texto-base, atende aos professores da Educação Básica ainda afeiçoados a métodos e encaminhamentos com os quais estão familiarizados desde a sua formação na Educação Básica, pois como evidenciam autores como Carvalho (2009), Boton (2015) e Caimi (2017), obras que empregam abordagens inovadoras são preteridas pelos professores em favor das que se adequam a métodos mais tradicionais. Já com a adição de discussões historiográficas recentes, problematização de fontes e da memória, presente nas caixas de texto, seções complementares e atividades, a literatura didática atende as prescrições escolares esboçadas pelo MEC que cada vez mais prezam pela adequação da literatura didática ao rigor científico e metodológico, conforme encaminham as prescrições dos editais do PNLD. Por fim, é imperativo destacar que esta estrutura, segundo nos parece, privilegia a versão canônica dos acontecimentos, já que reserva o principal espaço e maior parte das páginas para a exposição de uma narrativa que privilegia a memória, 
enquanto relega a espaços secundários a exposição de uma perspectiva que se opõe a tradição. ${ }^{10}$

Não obstante, a análise da narrativa didática acerca das Entradas e Bandeiras evidencia o caráter complexo dos livros didáticos de História e a especificidade do saber histórico que veiculam, participando da narrativa histórica escolar. Eles agregam diferentes camadas narrativas que veiculam construções da Memória e os saberes históricos resultantes da pesquisa sistemática. Convivem, em suas páginas, os mitos nacionais e a crítica elaborada com o objetivo de desconstruí-los. Esse aspecto da natureza do livro didático possibilita usos diversos do livro e enseja uma discussão promissora sobre a relação Memória/História, a construção de mitos e o potencial político das narrativas na construção de hierarquias, formulação de visões sobre o passado e projeções sobre o futuro. Elas ajudam a entender, também, a emergência de nativismos, entre outros fatores.

\section{Considerações Finais}

Neste texto buscamos discutir o livro didático e os saberes que ele incorpora, problematizando a narrativa didática sobre as Entradas e Bandeiras. Ao analisar as coleções didáticas selecionadas, identificamos que esta literatura apresenta diversas camadas narrativas. Aqui, tratamos de duas delas; uma ligada à Memória, disposta no texto principal e outra baseada no saber histórico profissional, abordada em espaços alheios ao texto-base.

A primeira camada reverbera perspectivas consolidadas por uma memória construída no final do século XIX e início do século XX que buscava transformar o bandeirante paulista em um símbolo que representasse a origem e os interesses paulistas. Com isso, o texto principal destaca, em grande parte, as descobertas e êxitos sertanistas, esquecendo ou amenizando as ações depredatórias desses sujeitos. O segundo estrato narrativo dos livros didáticos se apresenta em espaços alheios ao texto principal, como seções, caixas de texto e atividades, nestes recintos uma interpretação

\footnotetext{
${ }^{10} \mathrm{O}$ argumento que encaminhamos neste texto não pretende esgotar a análise sobre os fatores que concorrem para a permanência de determinada estrutura e um dado sentido das narrativas didáticas. Outros elementos concorrem para a permanência de uma narrativa canônica, concebida e aceita como a mais adequada. Nosso objetivo, no entanto, é, tão somente, problematizar como, nesse universo complexo, duas instâncias da cultura histórica - a Memória e a História - participam da narrativa e são operadas de modo a se conformarem em camadas narrativas que tornem os livros aceitos por um público mais amplo.
} 
diferente do movimento bandeirante ganha destaque, esta perspectiva baseada na historiografia recente problematiza e atualiza a produção oitocentista.

Ao analisar três coleções didáticas, confirmamos as constatações obtidas em estudos anteriores, já que os exemplares didáticos apresentaram duas camadas narrativas bem demarcadas nos diferentes espaços da estrutura. Os textos-bases delineavam aspectos cronológicos e característicos do tema, destacando as conquistas territoriais e minerais feitas pelos bandeirantes paulistas. Já as sessões alheias ao texto principal enfatizam discussões relativas à historiografia atual, problematizando a memória bandeirante e fontes históricas, acrescentando uma perspectiva distinta da esboçada pelo texto-base.

As camadas narrativas apontam o livro didático como um suporte cultural complexo. Ele expressa as tensões que o saber histórico escolar vivencia todas as vezes em que é acionado nas diversas salas de aula do país. Tal complexidade não encerra, necessariamente, um limite da literatura didática. Ao contrário, ela pode suscitar usos diversos do texto didático. A presença de ecos da Memória e de extratos do saber histórico profissional podem promover debates, problematizar perspectivas e fomentar uma aprendizagem mais significativa para crianças, adolescentes e adultos inseridos na Educação Básica.

\section{Referências}

ABREU, João Capistrano de. Capítulos de História Colonial (1500-1800). Brasília: Conselho Editorial do Senado Federal: 1998.

ABUD, Kátia Maria. O sangue intimorato e as nobilíssimas tradições - a construção de um símbolo paulista: o bandeirante. Tese (Doutorado em história), Universidade de São Paulo, São Paulo, 1986.

ALMEIDA, Emiliano Cesar. Retrato Paulista do Brasil: Paulo Prado, o Modernismo e a Semana de Arte Moderna de 1922. Letras Escreve, Amapá, v. 5, n. 2, p. 127-137, 2015.

AZEVEDO, Gislane Campos; SERIACOPI, Reinaldo. Coleção Projeto Teláris. 1 ed. São Paulo: Ática: 2012.

BRASIL. Guia de livros didáticos: PNLD 2014 - História. Brasília: Ministério da Educação, Secretaria de Educação Básica: 2013.

BRASIL. Guia de livros didáticos: PNLD 2017 - História. Brasília: Ministério da Educação, Secretaria de Educação: 2016. 
BOTON, Jaiane de Moraes. O processo de escolha do livro didático por professores: a evolução do PNLD e seus efeitos no ensino de ciências. Dissertação (Mestrado em Educação em ciências), Universidade Federal de Santa Maria, Santa Maria, 2014.

CAIMI, Flávia Eloísa. O livro didático de história e suas imperfeições: repercussões do PNLD após 20 anos. In: ROCHA, Helenice Aparecida Bastos; REZNIK, Luís; MAGAlHÃES, Marcelo de Souza. (orgs.). Livros Didáticos De História - Entre Políticas e Narrativas. 1ed. Rio de Janeiro: FGV Editora: 2017.

CAMPOS, Candido Malta. Os rumos da cidade: urbanismo e modernização. São Paulo: Senac: 2002.

CARBONELL, Charles-Olivier. Historiografia. Lisboa: Teorema: 1981.

CARVALHO, Ana Beatriz dos Santos. Leituras e usos do livro didático de história: relações professor - livro didático nos anos finais do ensino fundamental. Dissertação (Mestrado em educação), Universidade Federal de Uberlândia, Uberlândia, 2009.

CASTELO-BRANCO, Fernando. Tratado de Madri. In: SERRÃO, Joel (dir.). Vol. 4. Dicionário de História de Portugal. Porto: Livraria Figueirinhas: 1985.

CASSIANO, Célia Cristina de Figueiredo. O mercado do livro didático no Brasil: do Programa Nacional do Livro Didático - PNLD à entrada do capital internacional espanhol (1985-2007). Tese (Doutorado em Educação), Pontifícia Universidade Católica de São Paulo, São Paulo, 2007.

CHALOUB, Sidney; SILVA, Fernando Teixeira da. Sujeitos no imaginário acadêmico: escravos e trabalhadores na historiografia brasileira desde os anos 1980. Cadernos Arquivo Edgar Leuenroth, Campinas, v, 14, n. 26, 2009.

COELHO, Mauro Cezar. A história, o índio e o livro didático: apontamentos para uma reflexão sobre o saber histórico escolar. In: ROCHA, Helenice; Aparecida Bastos; REZNIK, Luiz; MAGALHÃES, Marcelo de Souza (orgs.). A história na escola: autores, livros e leituras. Rio de Janeiro: FGV: 2009.

COELHO, Mauro Cezar. Que enredo tem essa história? A colonização portuguesa na América nos livros didáticos de história. In: ROCHA, Helenice; REZNIK, Luis; MAGALHÃES, Marcelo de Souza. Livros didáticos de história: entre políticas e narrativas. Rio de Janeiro: FGV Editora: 2017.

CORTEZÃO, Jaime Zuzarte. O Tratado de Madrid. Brasília: Senado Federal: 2001.

ELLIS JUNIOR, Alfredo. Os Primeiros Troncos Paulistas e o cruzamento euroamericano. São Paulo: Companhia Editora Nacional: 1936.

FERREIRA, Marieta de Moraes; FRANCO, Renato. Desafios do ensino de história. Estudos Históricos, Rio de Janeiro, vol. 21, n. 41, p. 79-93, 2008.

GUIMARÃES, Manoel Luiz Salgado. Historiografia e nação no Brasil: 1838-1857. Rio de Janeiro: Ed. UERJ: 2011. 
JARDIM, Fernanda Maciel. O Design(er) na produção editorial do livro didático: funções, contribuições e limites. Dissertação (Mestrado em Design), Pontifícia Universidade Católica do Rio de Janeiro. Rio de Janeiro, 2010.

LE GOFF, Jacques. História e memória. Campinas: Editora da UNICAMP: 1996.

LESSA, Carlos. Nação e nacionalismo a partir da experiência brasileira. Estudos Avançados, São Paulo, v. 22, n. 62, p. 237-256, 2008.

MACHADO, Alcântara. Vida e morte do bandeirante. São Paulo: Edusp: 1980.

MATTOS, Ilmar Rohloff de. O Tempo Saquarema: a formação do Estado Imperial. São Paulo: HUCITEC: 1990.

MONTEIRO, John Manuel. Negros da terra: índios e bandeirantes nas origens de São Paulo. São Paulo: Companhia das Letras: 1994.

MONTEIRO, John Manuel. Tupis, tapuias e historiadores: estudos de história indígena e do indigenismo. Tese (Livre docência), Universidade estadual de Campinas. Campinas, 2001.

NOVO, Leonardo Castro. Os índios no ensino escolar de História do Brasil: seus lugares, suas representações (séculos XIX-XX). Dissertação (Mestrado em História Social), Universidade Federal do Pará, Belém, 2020.

PELLEGRINI, Marco César; DIAS, Adriana Machado; GRINBERG, Keila. Coleção Vontade de saber história. São Paulo: FTD: 2015.

QUEIROZ, Maria Isaura. Ufanismo paulista: vicissitudes de um imaginário. Revista USP, São Paulo, n.13, p.78-87, 1992.

RIBEIRO, Vanise Maria; ANASTASIA, Carla Maria Junho. Coleção Piatã. Curitiba: Positivo: 2015.

ROCHA, Helenice. A narrativa histórica nos livros didáticos, entre a unidade e a dispersão. Territórios e Fronteiras (Online), v. 6, p. 53-66, 2013.

SILVA, Marco Antônio. A fetichização do livro didático no Brasil. Educação \& Realidade, v.37, n.3, p. 803-821, 2012.

SILVA, Marco Antônio. História: Que Ensino é esse?. 1. ed. Campinas: Papirus: 2013. SOARES, José Carlos de Macedo. Fronteiras do Brasil no Regime Colonial. Rio de Janeiro: Livraria José Olympio Editora: 1939.

SOUZA, Ricardo Luiz. A mitologia bandeirante: construções e sentidos. Revista História Social, Campinas, v. 1 n. 13, 151-171, 2007.

TAMBS, Lewis A. Brazil's expanding frontiers. The Americas - Publication of The Academy of American Franciscan History, Washington (DC), v. 23, n. 2, p. 165-179, out. 1996. 
TAUNAY, Afonso d'Escragnolle. História Geral das Bandeiras. Volume I. São Paulo: Tipografia Ideal: 1924.

VARNHAGEN, Francisco Adolfo. História geral Brazil, tomo I. Madrid: Imprensa da V. de Dominguez: 1854.

WALDMAN, Thais Chang. A presença bandeirante na São Paulo dos anos 1920. In: REUNIÃO DE ANTROPOLOGIA DO MERCOSUL, XI, 2015, Montevideu. Anais da XI Reunião de Antropologia do Mercosul. Montevideu: Universidad de la Republica, 2015. p. 1-16 (Anais eletrônicos). 